\title{
Developing simple boranes as phase transfer catalysts for nucleophilic fluorination using CsF.t
}

\author{
Sven Kirschner ${ }^{a}$, Matthew Peters ${ }^{a}$, Kang Yuan ${ }^{a}$, Marina Uzelac ${ }^{a}$ and Michael J. Ingleson*a \\ a: EaStCHEM School of Chemistry, The University of Edinburgh, David Brewster Road, Edinburgh, EH9 3FJ, UK. \\ E-mail: michael.ingleson@edinburgh.ac.uk \\ †Electronic Supplementary Information (ESI) available: Full experimental procedures, DFT and crystallographic data.
}

Despite the general high fluorophilicity of boron, simple organoboranes such as $\mathrm{BEt}_{3}$ and $3,5-\left(\mathrm{CF}_{3}\right)_{2} \mathrm{C}_{6} \mathrm{H}_{3}-\mathrm{BPin}$ are shown herein for the first time, to our knowledge, to be effective phase-transfer catalysts for the fluorination of organohalides with CsF. Significant chiral induction during nucleophilic fluorination to form $\beta$-fluoroamines using oxazaborolidine (CBS) (pre)catalysts and CsF also can be achieved. Screening different boranes revealed a correlation between calculated fluoride affinity of the borane and nucleophilic fluorination reactivity, with sufficent fluoride affinity required for boranes to react with CsF and form Cs[fluoroborate] salts, but too high a fluoride affinity leading to fluoroborates that are poor at transferring fluoride to an electrophile. Fluoride affinity is only one component controlling reactivity in this context; effective fluorination also is dependent on the ligation of $\mathrm{Cs}^{+}$which effects the $\left[\mathrm{C}\right.$. $\left.\cdots \mathrm{F} \cdots \mathrm{BR}_{3}\right]$ interaction and thus the $\mathrm{B}-\mathrm{F}$ bond strength. Effective ligation of $\mathrm{Cs}^{+}$(such as by [2.2.2]-cryptand) weakens the Cs $\cdots F B$ interaction which strengthens the B-F bond - thus disfavours fluoride transfer to an electrophile. Combined these findings enables optimal fluorination outcomes to be expected using robust (to the fluorination conditions) boranes with fluoride affinity of ca. $110 \mathrm{~kJ} \mathrm{~mol}^{-1}$ (relative to $\mathrm{Me}_{3} \mathrm{Si}^{+}$) under conditions where a signficant Cs...F-B interaction persists.

\section{Introduction}

Boranes are ubiquitous in chemistry and most commonly utilised for their Lewis acidic character. The established dogma is that boranes $\left(\mathrm{BY}_{3}\right)$ are strong Lewis acids towards fluoride, with the derived fluoroborates, [F$B Y 3]^{-}$, being highly stable towards loss of fluoride.1 Many of the most widely used boranes, such as $B X_{3}(X=h a l i d e)$ and $B\left(\mathrm{C}_{6} \mathrm{~F}_{5}\right)_{3}$, are indeed strong Lewis acids towards fluoride and form robust fluoroborates, ${ }^{2}$ with $\left[\mathrm{BF}_{4}\right]^{-}$being an archetypal weakly coordinating anion. ${ }^{1}$ Furthermore, boranes such as $B\left(C_{6} F_{5}\right)_{3}$, and even $\mathrm{HBR}_{2}{ }^{3}$ are increasingly applied in defluorinative functionalisation of fluorocarbons, with fluoride abstraction by the borane to form a fluoroborate anion a key step (Figure 1). ${ }^{4}$ Thus using fluoroborates to transfer fluoride to carbon electrophiles appears counter intuitive. However, by controlling the relative Lewis acidity of the carbon and boron electrophiles it is possible to effect fluoride transfer from fluoroborates to carbon electrophiles. One classic example is [BF $]^{-}$ reacting as a stoichiometric fluoride source in the Balz-Schiemann reaction, but this requires a highly reactive Aryl ${ }^{+}$ electrophile. ${ }^{5}$ To expand the utility of fluoroborates in nucleophilic fluorinations it is highly desirable to: (i) use substoichiometric fluoroborate and stoichiometric MF, i.e. use boranes as MF phase transfer catalysts; (ii) fluorinate carbon electrophiles less reactive than e.g. Aryl'.

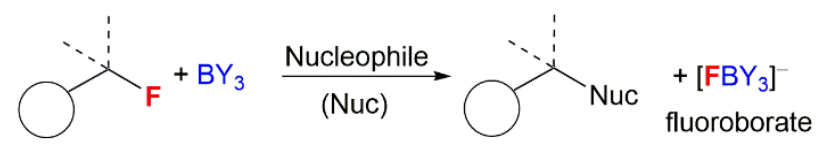

Figure 1: Established reactivity of boranes as fluorophilic Lewis acids. ${ }^{4}$

To expand the electrophile scope amenable to fluorination with fluoroborates requires an understanding of the factors controlling the fluoride ion affinity (FIA) of boranes, thereby enabling its rational modulation. Analysis of calculated FIA values reveals that borane fluorophilicity can be attenuated by: (i) the presence of significant $B=Y$ multiple bond character; (ii) reducing the positive charge localised at boron using less electron withdrawing substituents, and (iii) increasing the pyramidalisation energy at boron. ${ }^{6}$ The first two points combined explains the trend in the fluoride affinity of the simple boranes: $\mathrm{BF}_{3}$ (most Lewis acidic, $\left.\mathrm{FIA}=258 \mathrm{kJmol}^{-1}\right)>\mathrm{BMe}_{3}(\mathrm{FIA}=132$ $\left.\mathrm{kJmol}^{-1}\right)>\mathrm{B}(\mathrm{OH})_{3}\left(\mathrm{FIA}=106 \mathrm{kJmol}^{-1}\right.$, $\mathrm{FIA}$ values relative to $\left.\mathrm{Me}_{3} \mathrm{Si}^{+}\right) .{ }^{6}$ Despite the facile ability to tune fluoride affinity at boron there are no reports, to the best of our knowledge, that utilise low FIA boranes as catalysts for MF phase transfer fluorination. Due to the importance of fluorinated molecules in pharmaceuticals and agrochemicals ${ }^{7}$ and the attractive nature of using metal fluoride (MF) salts and simple boranes to effect nucleophilic fluorination, we 
sought to: (i) demonstrate that low fluoride affinity boranes can be used as MF phase transfer catalysts and (ii) develop the structure activity relationships key to enabling this reactivity.

Phase transfer catalysts are well established in the field of nucleophilic fluorination as the low solubility of MF in non-protic solvents (required for sufficient fluoride nucleophilicity) necessitates their use. ${ }^{8,}$ 9a Established phase transfer agents include metal chelators (e.g. cryptands), organic cations (e.g. $\left.\left[\mathrm{R}_{4} \mathrm{~N}\right]^{+}\right),{ }^{9}$ Lewis acids that weakly bind fluoride (e.g. in hypercoordinated silicates) and compounds that function as multiple hydrogen bond donors to fluoride. ${ }^{8,9}$ Boranes with low FIA (relative to $\mathrm{BF}_{3}$ ) have been largely overlooked in this area. Even the stoichiometric use of fluoroborates derived from lower fluoride affinity boranes in nucleophilic fluorination is rare, with the very limited exceptions including the use of PinBF in the ring opening fluorination of epoxides ${ }^{10}$ and the use of fluoroborate $\mathbf{A}$ (Figure 2, top) to fluorinate a range of organic electrophiles. ${ }^{11}$ In the latter, formation of a $\mathrm{B} \leftarrow \mathrm{SR}_{2}$ dative bond contributes to making fluoride transfer from boron to carbon thermodynamically favourable. This factor will be absent using simpler, Lewis base free, boranes in MF phase transfer / nucleophilic fluorination cycles (Figure 2, bottom).
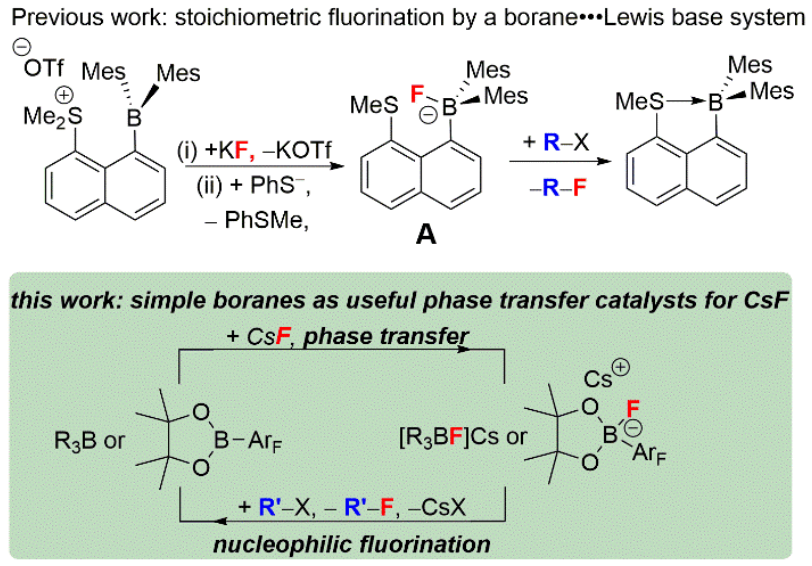

Figure 2: Top: stoichiometric fluorination using a dative bond donor functionalised borane. Bottom: this work using simple boranes as MF phase transfer catalysts.

Herein we demonstrate that simple boranes are useful CSF phase transfer fluorination catalysts. Furthermore, we have elucidated a number of the important factors controlling the effectiveness of low FIA boranes as CsF phase transfer fluorination catalysts. Demonstrating that simple boranes can act as CsF phase transfer fluorination catalysts opens the door to using the plethora of readily synthesised enantioenriched boranes ${ }^{12}$ in enantioselective nucleophilic fluorination.

\section{Results and Discussion}

Initially we sought to determine if the fluoroborates derived from low fluoride affinity triorganoboranes will transfer fluoride to weaker (than $\mathrm{Aryl}^{+}$) carbon electrophiles, as suggested by previous computational studies. ${ }^{13}$ For these initial studies $\left[\mathrm{NMe}_{4}\right]^{+}$salts were used to minimise any complications associated with strong interactions between anion and cation. In contrast, significant $R_{3} B \cdots F \cdots M(M=$ group 1 metal cation) interactions are expected, particularly in weakly coordinating solvents, which could significantly modify fluorination reactivity using MF salts. $\left[\mathrm{NMe}_{4}\right]\left[\mathrm{FBPh}_{3}\right]$ was synthesised by combination of $\mathrm{BPh}_{3}$ and $\left[\mathrm{NMe}_{4}\right][\mathrm{F}]$ and combined with $\left[\mathrm{Ph}_{3} \mathrm{C}\right]\left[\mathrm{B}\left(\mathrm{C}_{6} \mathrm{~F}_{5}\right)_{4}\right]$. This resulted in fluoride transfer from boron to carbon as indicated by ${ }^{11} \mathrm{~B}$ (change in $\delta_{11 \mathrm{~B}}$ from 3.4 for [FBPh$]^{-}$to 60.5 for $\left.\mathrm{BPh}_{3}\right)$ and ${ }^{19} \mathrm{~F} \mathrm{NMR} \mathrm{spectroscopy}\left(\mathrm{Ph}_{3} \mathrm{CF}\right.$ observed as the major product, $\left.\delta_{19 \mathrm{~F}}=126.6\right)$. The use of the ethyl congener, $\left[\mathrm{NMe}_{4}\right]\left[\mathrm{FBEt}_{3}\right]$, resulted in an analogous outcome ( $\mathrm{BEt}_{3}$ and $\mathrm{Ph}_{3} \mathrm{CF}$ formation). Therefore in contrast to $\left[\mathrm{BF}_{4}\right]^{-}$(which is stable with respect to fluoride transfer to $\mathrm{Ph}_{3} \mathrm{C}^{+}$), these $\left[\mathrm{R}_{3} \mathrm{BF}\right]^{-}$anions can transfer fluoride to weaker (than $\mathrm{Aryl}^{+}$) carbon electrophiles.

To guide subsequent studies and identify other boranes with potential as phase transfer fluorination catalysts we calculated fluoride ion affinity values using a closely related method to that reported by Greb et $a l .{ }^{6}$ These values are a useful initial indicator of utility in this context, as sufficient fluoride affinity is required for the borane to react with MF and form the fluoroborate salt, but if the FIA is too great then subsequent transfer of fluoride from the fluoroborate to an electrophile will be disfavoured. Therefore the borane with the lowest fluoride affinity value that enables phase transfer of a MF salt was our initial target as this should have the maximum fluorination scope as it will form the most nucleophilic fluoroborate (i.e. the fluoroborate with the weakest B-F bond). 
These calculations (Figure 3) enabled us to identify commercially available or readily synthesised boranes (including two enantioenriched examples) spanning a range of fluoride affinity values for study, with the value for $\mathrm{BF}_{3}$ at this level provided for comparison. The calculations were consistent with the expected outcomes e.g. electron withdrawing groups (in 1-3) increase fluoride affinity (relative to PhBPin). While increased multiple bond character, e.g. $B=N R_{2}$ double bond character being greater than $B=O R$ double bond character, leads to $C B S$ catalyst 4 being a weaker Lewis acid towards fluoride than PhBPin. Several boranes with very similar calculated fluoride affinity values also were identified to probe the effect different functional groups (e.g. $\mathrm{NO}_{2} \mathrm{Vs} \mathrm{CF}_{3}$ in $\mathbf{1}$ and $\mathbf{3}$ ) and substituent size (e.g. $\mathrm{BEt}_{3} \mathrm{Vs}_{5}$ ) have on reacting with MF and controlling the subsequent reactivity of the fluoroborate. This is important as in contrast to $\left[\mathrm{R}_{4} \mathrm{~N}\right]^{+}$, the solvation of $\mathrm{M}^{+}$and $\mathrm{F}^{-}$needs to be considered along with the effect of any strong interactions between $\mathrm{M}^{+}$and the fluoride of the fluoroborate persisting in solution.

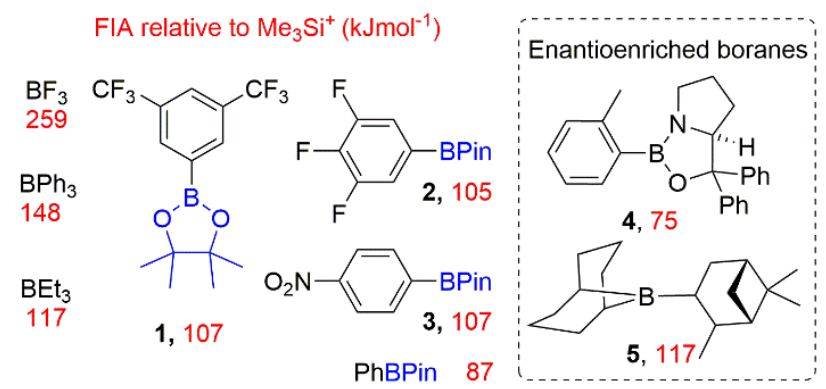

Figure 3: Boranes employed as phase transfer catalysts in this study and their respective calculated (at the DSD-BLYP-D3(BJ)/def2TZVP level with $\mathrm{SMD} \mathrm{CH}_{2} \mathrm{Cl}_{2}$ ) fluoride ion affinity (FIA, red).

\section{Nucleophilic Fluorination with CsF}

Fluorination of 6 to form $\beta$-fluoroamine, 7, using MF catalysed by boranes was explored as a test reaction to determine if there is any correlation between borane fluoride affinity and phase transfer / nucleophilic fluorination reactivity (Table 1).

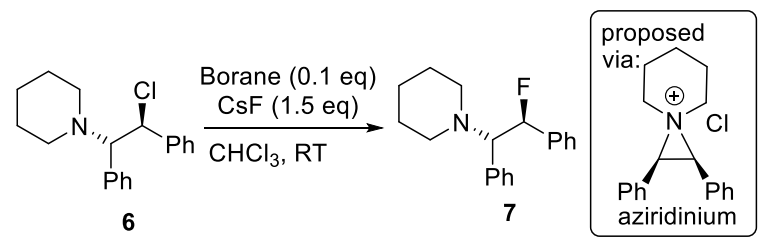

Table 1: Outcome of fluorination depending on the borane catalyst.

\begin{tabular}{|c|c|c|c|}
\hline Borane & FIA $\left(\mathrm{kJ} \cdot \mathrm{mol}^{-1}\right)$ & Time (h) & Yield /\% \\
\hline $\mathrm{B}\left(\mathrm{C}_{6} \mathrm{~F}_{5}\right)_{3}$ & $254^{a}$ & 24 & $<5^{b}$ \\
\hline $\mathrm{BPh}_{3}$ & 148 & 24 & $40^{b}$ \\
\hline $\mathrm{BEt}_{3}$ & 117 & 24 & 88 \\
\hline 1 & 107 & 7 & 89 \\
\hline 2 & 105 & 18 & 73 \\
\hline 3 & 107 & 24 & $17^{b}$ \\
\hline PhBPin & 87 & 24 & $26^{b}$ \\
\hline
\end{tabular}

Reaction conditions: 6 (0.2 mmol), borane (10 mol\%), $\mathrm{CsF}(0.3 \mathrm{mmol}), \mathrm{CHCl}_{3}$ (anhyd., $5 \mathrm{~mL}$ ), room temperature, $1000 \mathrm{rpm}$. a: value from ref 6; b: conversion (by ${ }^{1} \mathrm{H}$ NMR integration of 7 vs 6 ).

Attempts to perform fluorination of 6 with $\mathrm{KF}$ (with ${ }_{1} / \mathrm{BEt}_{3}$ as catalysts) led to no fluorination in $\mathrm{CHCl}_{3}$, thus all further fluorination studies were performed using CsF. With both $\mathrm{BEt}_{3}$ and ArBPin based boranes haloalkane solvents gave better outcomes than other solvents, e.g. MeCN, thus only results in DCM or chloroform are discussed. Note a control reaction in the absence of borane led to no fluorination with CsF under these conditions. From this study phase transfer fluorination of 6 using CsF was effective with both $10 \mathrm{~mol}^{\circ} \mathrm{BEt}_{3}$ and $\mathbf{1}$. This demonstrates that borane phase transfer catalysts can be used to access important fluorinated molecules. ${ }^{8}$ As expected the identity of the borane is all important, with weaker Lewis acids e.g. PhBPin, and stronger Lewis acids (e.g. $\mathrm{BPh}_{3}$ ) both giving poorer outcomes. The former is consistent with a minimum fluoride affinity being required to form the Cs[fluoroborate] salt, while the latter indicates that if the fluoride affinity is too high then this disfavours transfer of fluoride from boron in the fluoroborate to the electrophile (fluoroborate formation is observed with 
higher FIA boranes). However, there are additional factors beyond fluoride affinity controlling fluorination using boranes, as $\mathbf{3}$ was a relatively poor catalyst despite having an identical calculated fluoride affinity to 1.

A brief electrophile scoping study was performed using $\mathrm{BEt}_{3}$ and $\mathbf{1}$ as catalysts and this revealed the fluoroborates derived from these boranes to be poorer sources of fluoride relative to the Lewis base incorporated borate A. For example, no fluorination of octyl bromide or benzyl halides was observed even after prolonged periods refluxing with excess borane/CsF (Scheme 1). In contrast, using two eq. of $\mathbf{A}$ generated high yields of $\mathrm{PhCH}_{2} \mathrm{~F}^{11 a}$ demonstrating the positive effect the $\mathrm{B} \leftarrow \mathrm{SR}_{2}$ dative bond has in enhancing fluoride transfer ability.

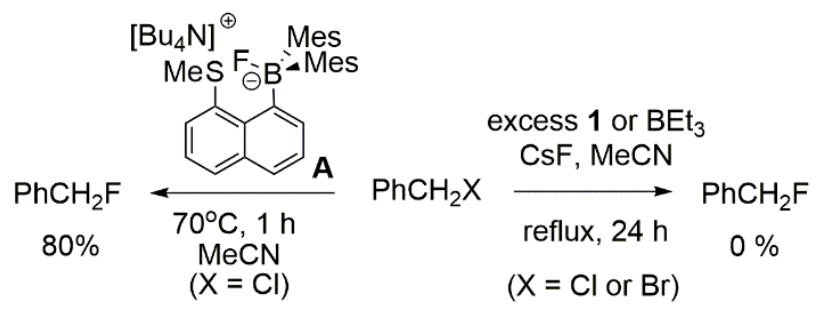

Scheme 1: Disparate outcomes in the fluorination of benzyl halides with boranes.

Stronger electrophiles (than $\mathrm{PhCH}_{2} \mathrm{Br}$ ) did undergo fluorination with $\mathrm{CsF}$ using 1 / $\mathrm{BEt}_{3}$ as catalysts. Reaction of $\beta$-bromo sulphide $\mathbf{8}$ with $\mathrm{CsF}$ with either $\mathrm{BEt}_{3}$ or $\mathbf{1}$ as catalyst in $\mathrm{CHCl}_{3}$ led to significant formation of stilbene (mixture of cis-trans isomers) with only traces of $\mathbf{9}$ formed. Serendipitously, we found that the outcome of this reaction is effected dramatically by solvent. Using $\mathrm{DCM} / n$-hexane $(6: 1)$ as the reaction medium, stilbene formation was negligible (ca $3 \%$ ) and 9 could be formed in moderate yield using $\mathrm{BEt}_{3}$ (Figure 4). We attribute this disparity to the solvent effecting the equilibrium position between $\mathbf{8}$ and the thiiranium cation essential for fluorination. ${ }^{8}$ Reaction of $\mathrm{Ph}_{3} \mathrm{CCl}$ with $\mathrm{CsF}$ in $\mathrm{CHCl}_{3}$ catalysed by either $\mathrm{BEt}_{3}$ or 1 proceeded in moderate to good yield. Benzoyl chloride proved to be more challenging, with 1 as the catalyst fluorination proceeded to only ca. $5 \%$ conversion. However, using $10 \mathrm{~mol}^{\mathrm{B}} \mathrm{BEt}_{3}$ benzoyl fluoride was formed in good yield.
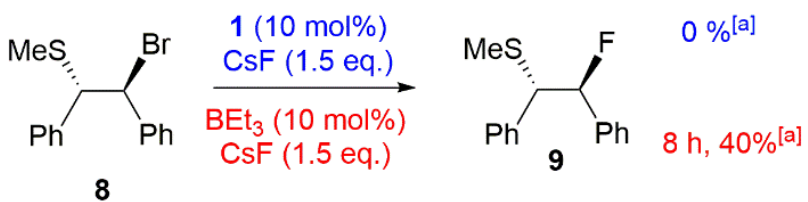

8

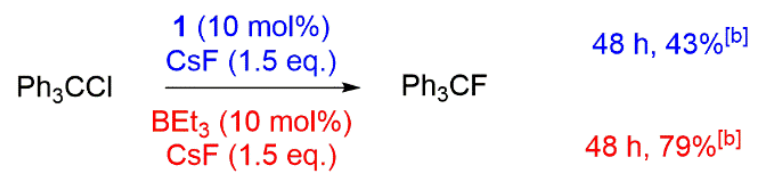

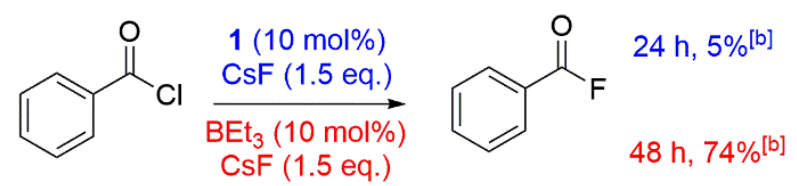

Figure 4: Scope of the borane catalysed fluorination reaction. Conditions: substrate $(0.2 \mathrm{mmol}), \mathrm{CsF}(0.3 \mathrm{mmol})$, borane (10 mol\%), $\mathrm{CHCl}$ (anhyd., $5 \mathrm{~mL}$ ), room temperature, $1000 \mathrm{rpm}$. a: reaction performed in $\mathrm{DCM} / \mathrm{n}$-hexane $=6: 1$; b: conversion gauged by ${ }^{19} \mathrm{~F}$ qNMR vs. 1 ,2difluorobenzene as internal standard.

\section{Enantioselective Fluorination Studies}

One attractive feature of using boranes as CsF phase transfer fluorination catalysts is the ready accessibility of many enantioenriched boranes. ${ }^{12}$ Herein $\mathbf{4}$ and $\mathbf{5}$ were assessed in the enantioselective fluorination of $\mathbf{6}$ and $\mathbf{8}$ (which proceed via ring opening of the meso aziridinium and thiiranium cations, respectively). ${ }^{8}$ While $\mathbf{5}$ was ineffective as a catalyst in halocarbon solvents, it did function in the presence of MeCN. However, the use of stoichiometric Cs[5-F] in DCM/MeCN mixtures while leading to formation of $\mathbf{7}$ and $\mathbf{9}$, resulted in no e.e. being 
observed by chiral HPLC analysis. Furthermore, significant amounts of the hydrodehalogenation also was observed using Cs[5-F] alongside formation of 7/9, possibly via a mechanism related to the Midland reduction (Scheme 2). ${ }^{12 c}$

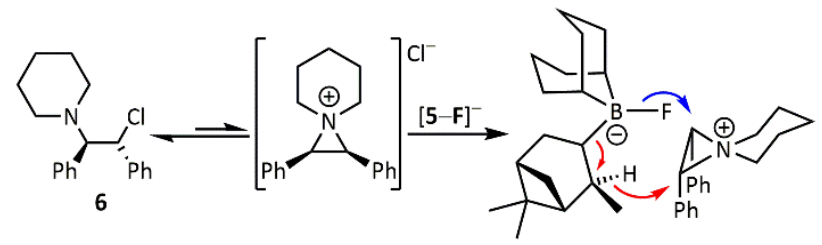

Scheme 2: Fluorination of $\mathbf{6}$ (and 8) with Cs[5-F] (blue arrow) competes with Midland type reduction (red arrows).

The use of commercially available CBS catalyst 4 ( $0.5 \mathrm{M}$ in toluene) also was explored as it is not prone to loss of hydride. Surprisingly (given its low calculated fluoride affinity), as received $\mathbf{4}$ effectively catalysed fluorination of 6 with $\mathrm{CsF}$ and led to appreciable e.e. in $\mathbf{7}$ (maximum e.e. observed using commercial $\mathbf{4}$ was in $\mathrm{CHCl}_{3}$ at $20{ }^{\circ} \mathrm{C}=30 \%$ e.e.). ${ }^{14}$ In addition to 7 , ca. $5 \%$ of the $\beta$-amino-alcohol, 10 , was formed at early stages of the reaction, attributed to the presence of low quantities of water that leads to hydroxide transfer to $6 .{ }^{15} \mathrm{~A}$ range of CBS catalysts were bought or made (see supporting information) and used as crude mixtures (as per CBS-catalysed hydroboration procedures). However, none gave better e.e. than commercial $\mathbf{4}$ in the catalytic fluorination of $\mathbf{6}$ with CsF. Notably, commercial CBS catalyst 11, supplied as a solid, only enabled fluorination after an induction period. Due to this disparity detailed analysis of the commercial batches of $\mathbf{4}$ and $\mathbf{1 1}$ was performed. This revealed a number of impurities present at significant levels (upto $30 \%$ by ${ }^{11} \mathrm{~B}$ NMR spectroscopy), including resonances consistent with products derived from reaction of 4/11 with water as previously reported (e.g. 12/13/14; Figure 5). ${ }^{16}$

$$
\begin{aligned}
& \overbrace{\mathrm{B}^{\prime}-\mathrm{O}}^{\mathrm{Ar}} \mathrm{Ar} \\
& \text { (Ar } \\
& \mathrm{Ar}=\mathrm{Ph}, \mathrm{R}=\mathrm{o} \text {-tolyl }=4 \\
& 12 \\
& \mathrm{~N}_{\mathrm{R}}^{\mathrm{Ar}} \mathrm{Ar} \\
& \mathrm{Ar}=\mathrm{Ph}, \mathrm{R}=\mathrm{Me}=11
\end{aligned}
$$

Figure 5: Structures of compounds present in commercial sourced CBS catalyst.

Attempts were made to isolate high purity CBS catalysts for further studies. This proved challenging, but the formation of several in significantly higher purity (ca. 90 - 99\% purity) than the commercial material was achieved. ${ }^{17}$ These higher purity CBS catalysts gave worse outcomes than using commercial batches of $\mathbf{4}$ in the fluorination of $\mathbf{6}$ with CsF. In addition, all > 90\% purity CBS catalysts (including independently synthesised 4, termed "higher purity 4") displayed an induction period before significant fluorination occurred (Figure 6). This indicated that CBS catalysts are actually pre-catalysts for phase transfer fluorination. It should be noted that $\mathbf{1}$ and $\mathrm{BEt}_{3}$ did not display induction periods during the fluorination of 6 under identical conditions. Attempts were made to elucidate the structure of the catalytically active species derived from CBS pre-catalysts under fluorination conditions, however this study was inconclusive, and these results can be found in the ESI.

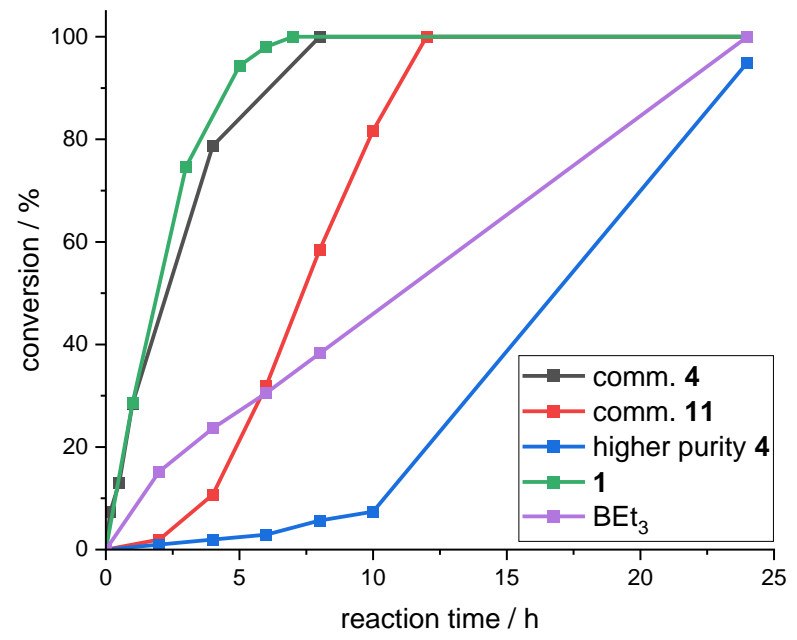

Figure 6: Plots of conversion (by ${ }^{1} \mathrm{H}$ NMR integration of 7 vs 6 ) vs. time for the fluorination of 6 with CsF catalysed by either 10 mol\% 1 , $\mathrm{BEt}_{3}, \mathbf{4}$ (commercial and independently synthesised) and $\mathbf{1 1}$ (commercial). 
While this work with CBS (pre)catalysts provides proof of principle that enantioselective borane phase transfer fluorination catalysis is feasible, the ill-defined and complex mixtures produced using CBS (pre)catalysts under these conditions is a complicating factor presumably contributing to the maximum e.e. being $30 \%$, despite using multiple CBS (pre)catalyst structures. This highlights the importance of using borane catalysts that are robust under these conditions to allow for rational control of reactivity (note under these fluorination conditions both 1 and BEt 3 show no observable decomposition, e.g. by protodeboronation or pinacol hydrolysis).

\section{MF Binding Studies}

To understand why only certain borane/MF combinations are effective fluorination catalysts, their ability to form M[fluoroborate] salts was explored initially. With $\mathrm{BEt}_{3}$ and with $\mathbf{1 / 2}$ no change to the NMR spectra (including the amount of borane observed in solution vs. an internal standard) was observed on addition to KF suspended in $\mathrm{CHCl}_{3}$, consistent with the high lattice enthalpy of $\mathrm{KF}$ relative to $\mathrm{CsF}\left(\mathrm{KF}=194.4 \mathrm{kcal} \cdot \mathrm{mol}^{-1}\right.$ and $\mathrm{CsF}=178.7 \mathrm{kcal} \cdot \mathrm{mol}^{-}$ $\left.{ }^{1}\right)^{18}$ leading to no reaction and thus no fluorination of 6 using these boranes/KF. In contrast, combining BEt 3 with $\mathrm{CsF}$ formed the fluoroborate in a range of solvents (Table 2). Notably, the NMR spectra for Cs[FBEt $\left.{ }_{3}\right]$ were $^{2}$ significantly different in $\mathrm{DCM} / \mathrm{CDCl}_{3}$ (entries 1 and 2) compared to those in MeCN (entry 3), with this solvent dependence attributed to a different aggregation of the Cs[FBEt 3 salt. This is supported by DOSY NMR studies which indicated $\left[\mathrm{FBEt}_{3}\right]^{-}$was a monomer in MeCN, but exists in larger aggregates in $\mathrm{DCM}\left(\left[\mathrm{Cs}\left(\mathrm{FBEt}_{3}\right)\right]_{n}\right.$ with $n>1$, vide infra). This is attributed to $\mathrm{MeCN}$ being more effective at ligating $\mathrm{Cs}^{+}$than halocarbon solvents, breaking up $\mathrm{Cs}_{n}(\mu-$ $\mathrm{F})_{n}(n>1)$ units. A related process would explain the addition of [2.2.2]-cryptand (1.25 eq) to $\left.\mathrm{Cs}_{\text {[ }} \mathrm{FBEt}_{3}\right]$ in halocarbon solvents resulting in a considerable shift in fluoroborate resonances (entries 2 and 4). The cryptand by binding $\mathrm{CS}^{+}$ will weaken the $\mathrm{B}-\mathrm{F} \cdots \mathrm{Cs}$ interaction which will increase the $\mathrm{B}-\mathrm{F}$ bond strength (vide infra).

Table 2: Select ${ }^{11} \mathrm{~B}$ and ${ }^{19} \mathrm{~F}$ chemical shifts (in ppm) of mixtures of boranes with CsF in various solvents. Crypt $=[2.2 .2]$-cryptand; $n . r .:$ not resolved; n.d.: not detected.

\begin{tabular}{ccccc}
$\#$ & Conditions & $\delta_{11 \mathrm{~B}}$ & $\delta_{19 \mathrm{~F}}$ & ${ }^{1} J_{\mathrm{BF}} / \mathrm{Hz}$ \\
\hline 1 & $\mathrm{BEt}_{3} / \mathrm{CsF} / \mathrm{CDCl}_{3}$ & 11.2 & -148.3 & $n . r$. \\
2 & $\mathrm{BEt}_{3} / \mathrm{CsF} / \mathrm{DCM}$ & 9.8 & -148.3 & $n . r$. \\
3 & $\mathrm{BEt}_{3} / \mathrm{CsF} / \mathrm{MeCN}$ & 5.4 & -178.9 & 63 \\
4 & $\mathrm{BEt}_{3} / \mathrm{CsF} / \mathrm{DCM} / \mathrm{crypt}$ & 5.2 & -192.0 & $89 \mathrm{a}$ \\
5 & $\mathrm{BEt}_{3} / \mathrm{CsF} / \mathrm{MeCN} / \mathrm{crypt}$ & 4.5 & -190.2 & 88 \\
6 & $\mathbf{1} / \mathrm{CsF} / \mathrm{CDCl}_{3}$ & $n . d$. & $n . d$. & $n . d$. \\
7 & $\mathbf{1} / \mathrm{CsF} / \mathrm{MeCN}^{2}$ & 7.4 & -130.2 & 72 \\
8 & $\mathbf{1} / \mathrm{CsF} / \mathrm{CDCl}_{3} / \mathrm{crypt}$ & 2.9 & -144.4 & n.r. \\
9 & $\mathbf{5} / \mathrm{CsF} / \mathrm{MeCN}^{2}$ & 4.1 & -153.6 & 80 \\
\hline
\end{tabular}

$\mathrm{a}=$ no ${ }^{1} \mathrm{~J}_{\mathrm{BF}}$ resolved when run in $\mathrm{CDCl}_{3}$, thus data in DCM reported.

As expected, [2.2.2]-cryptand more strongly ligates $\mathrm{Cs}^{+}$than $\mathrm{MeCN}$ (confirmed by addition of [2.2.2]-cryptand to a MeCN solution of Cs[FBEt 3 causing a shift from $\delta_{19 \mathrm{~F}}=-178.9$ to $\delta_{19 \mathrm{~F}}=-190.2$ (entry 3 vs 5 ) indicating displacement of $\mathrm{MeCN}$ from $\mathrm{Cs}^{+}$by cryptand. The different chemical shifts and coupling constants observed suggests significantly different $\mathrm{B}-\mathrm{F}$ bond strengths in these systems, presumably due to different Cs $\cdots \mathrm{F}-\mathrm{B}$ interactions. Therefore $\mathrm{Cs}^{+}$ ligation will effect not just the phase transfer of $\mathrm{CsF}$ using boranes, but also the ability of the formed $\mathrm{Cs}\left[\mathrm{FBR}_{3}\right]$ to act as a nucleophilic source of fluoride. The NMR data indicate that $\mathrm{CsF}_{\mathrm{BRR}}$ in halocarbon solvents (e.g. entries $1 / 2$ ) should be the most nucleophilic source of fluoride, due to the downfield shifted ${ }^{11} \mathrm{~B}$ resonance (which is generally associated with less electron density located at boron which would correlate with a weaker B-F bond in this context). This is consistent with the catalytic fluorination results where halocarbon solvents gave better outcomes than using MeCN.

Moving to dioxaborolanes, with ArBPin/CsF combinations only the free ArBPin was visible by NMR spectroscopy in halocarbon solvents, although solid is present in these reactions. Assessing these mixtures by NMR spectroscopy using an internal standard revealed a significant decrease in the intensity of ArBPin resonances on addition of CsF for $\mathbf{1}$ and $\mathbf{2}$. This indicates the formation of poorly soluble (in halocarbon) fluoroborate salts derived from $\mathbf{1}$ and $\mathbf{2}$. Thus $\mathbf{1}$ and $\mathbf{2}$ do react with CSF consistent with their ability to catalyse fluorination using these solvents. In contrast, no evidence for formation of the fluoroborate was observed on combining CsF/PhBPin (by NMR spectroscopy versus an internal standard which showed no decrease in the amount of PhBPin present in halocarbon solutions). The disparity can be attributed to the lower fluoride affinity of PhBPin which will disfavour reaction with CsF and is presumably why PhBPin is a poor catalyst for nucleophilic fluorination of $\mathbf{6}$. The para-nitro derivative, $\mathbf{3}$, also showed 
no reaction with $\mathrm{CsF}$ in $\mathrm{CDCl}_{3}$ (by NMR spectroscopy versus an internal standard), despite $\mathbf{3}$ having an effectively identical calculated fluoride affinity to that for $\mathbf{1}$. This is consistent with the relatively poor catalytic performance of $\mathbf{3}$ in the fluorination of $\mathbf{6}$ (Table 1). Furthermore, in MeCN while $\mathbf{1 / 2}$ are converted completely to soluble fluoroborates on reaction with CsF (e.g. Table 2, entry 7), combining 3 with excess CsF in MeCN led to only ca. $10 \%$ of $\mathrm{Cs}[3-\mathrm{F}]$, with 3 being the dominant boron containing species observed in MeCN solution. Thus despite a similar calculated fluoride affinity to $\mathbf{1}$, borane $\mathbf{3}$ is much less disposed to react with CsF in a range of solvents. We propose that this is due to a sufficiently different (to effect reactivity) magnitude of interaction with the $\mathrm{Cs}^{+}$cation in the fluoroborates derived from 1-3. This is tentatively attributed to the C-F...Cs ${ }^{+}$interactions expected using 1 and 2 being stronger than $\mathrm{NO}_{2} \cdots \mathrm{Cs}^{+}$interactions expected when using 3. Multiple short $\mathrm{C}-\mathrm{F} \cdots \mathrm{Cs}$ contacts are present in the solid-state structure of the related salt $\mathrm{Cs}\left[\mathrm{FB}\left(\right.\right.$ neop) $\left.\left(\mathrm{C}_{6} \mathrm{H}_{3}\left(\mathrm{CF}_{3}\right)_{2}\right)\right]$ (B; Figure 8), ${ }^{19}$ which may persist to some extent in solution. Notably, while B was crystallised from THF/pentane no THF was present in the structure coordinating to $\mathrm{Cs}^{+}$, instead a distorted $\mathrm{Cs}_{4} \mathrm{~F}_{4}$ cubane is formed, with further ligation of $\mathrm{Cs}^{+}$by neop $\mathrm{O} \cdots \mathrm{Cs}$ and $\mathrm{C}-\mathrm{F} \cdots \mathrm{Cs}$ interactions (Figure 8). The tetrameric nature of the structure of $\mathbf{B}$ highlights the propensity of $\mathrm{Cs}$ [fluoroborates] to oligomerise in the absence of additional good ligands for caesium.
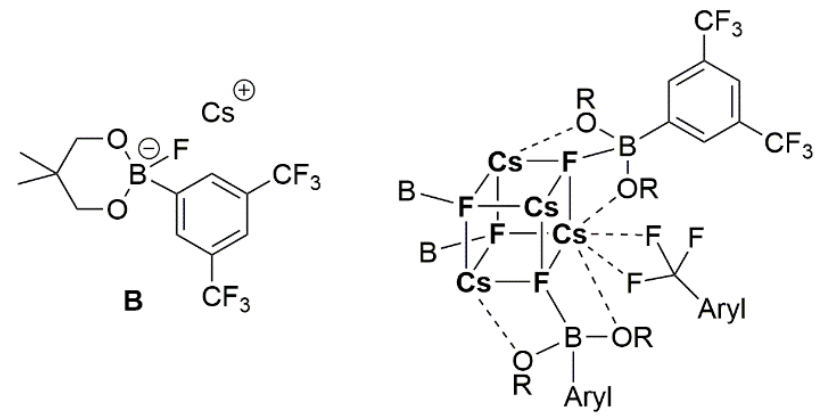

Figure 8: Left: compound B; right: representation of the partial extended solid state structure of $\mathbf{B}$, highlighting the ligation of one Cs centre by both neop $\mathrm{O}$ and $\mathrm{F}-\mathrm{C}$.

The effect of [2.2.2]-cryptand on Cs[fluoroborate] speciation again was explored. A mixture of 1 / [2.2.2]cryptand and excess CsF gave a halocarbon soluble product (Table 2, entry 8), with $\delta_{11 \mathrm{~B}}=2.9$ and $\delta_{19 \mathrm{~F}}=-144.4$, albeit both resonances being broad with no resolved B-F coupling. The upfield shift in $\delta_{11 \mathrm{~B}}$ suggests adding cryptand leads to stronger B-F binding, presumably by weakening the Cs...F-B interaction. This should disfavour nucleophilic fluorination by the fluoroborate, which indeed is what was observed. Specifically, the use of a 1:1 combination of 1/[2.2.2]-cryptand retarded fluorination of 6 with CsF (relative to fluorination of 6 using just 1 or using just [2.2.2]cryptand, Scheme 3) despite CsF phase transfer being observed to form the fluoroborate in all cases. Thus [2.2.2]cryptand more effectively sequesters $\mathrm{Cs}^{+}$leading to a relatively strong B-F bond in the fluoroborate that is a poorer nucleophilic source of fluoride. This clearly highlights that while the optimal borane fluoride affinity is vital for effective nucleophilic phase transfer fluorination, so is controlling caesium ligation and thus the magnitude of the Cs $\cdots$ F-B interaction.

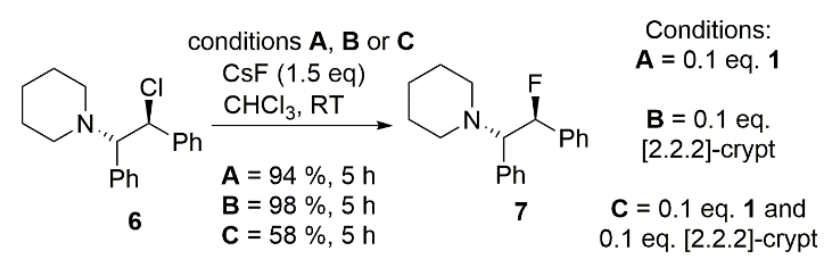

Scheme 3: Effect of cryptand/borane on phase transfer fluorination with CsF.

Finally, borane $\mathbf{5}$ was studied as it is a triorganoborane with the same calculated fluoride affinity as BEt but a $_{3}$ different environment around the boron centre, which significantly impacts its performance in catalysing nucleophilic fluorination (vide supra). Compound $\mathbf{5}$ showed no propensity to bind fluoride in halocarbon solvents (by NMR spectroscopy) in contrast to $\mathrm{BEt}_{3}$, consistent with the disparate catalytic nucleophilic fluorination performance observed in DCM. This further confirms that calculated fluoride affinity values must be used with caution for predicting reactivity when there is a coordinating cation present. Using $\mathrm{DCM} / \mathrm{MeCN}$ mixtures or neat MeCN did enable formation of the fluoroborate, $\mathrm{Cs}[5-\mathrm{F}]\left(\delta_{11 \mathrm{~B}}=4.1 \mathrm{ppm}{ }^{1} J_{\mathrm{BF}}=80 \mathrm{~Hz}, \delta_{19 \mathrm{~F}}=-153.6\right)$, consistent with the observation of fluorination using this borane in these solvents. This again indicates that interaction of $\mathrm{Cs}^{+}$with MeCN provides a significant contribution to the solubilisation of CsF. 

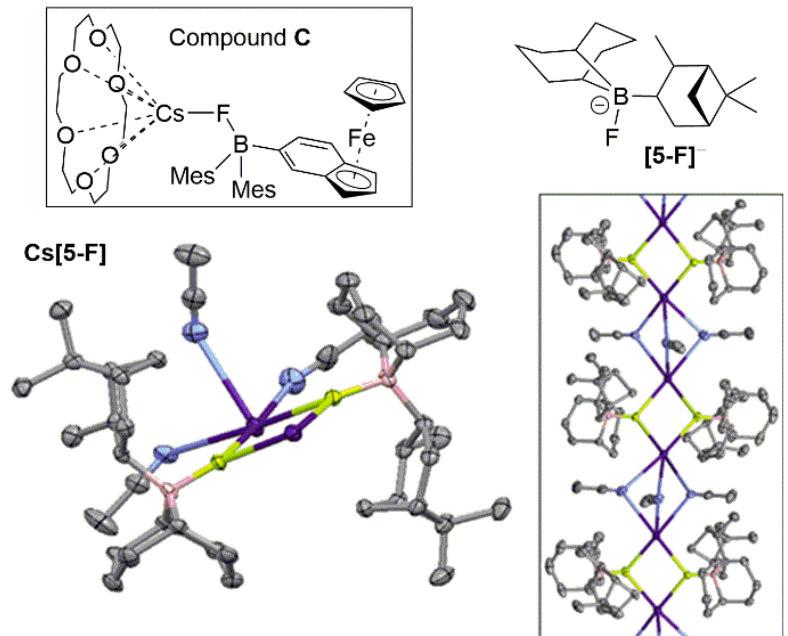

Figure 9: Top, compounds $\mathrm{C}$ and [5-F]-. Bottom left, one $\mathrm{CS}_{2}\left(\mathrm{FBR}_{3}\right)_{2}$ unit. Inset right, the extended 1D polymeric structure of MeCN solvated

Cs[5-F]. Yellow = F, pink = B, purple = Cs, blue = N, grey = C. Selected bond distances $(\AA)$ and angles $\left({ }^{\circ}\right)$ in Cs $[5-F]: B-F=1.524(5)$ and 1.526(6); Cs-F = 2.862(3) - 2.945(3); Cs-N = 3.190(5) - 3.245(5); B-C = 1.616(9) - 1.650(8); F-Cs-F = 73.97(8) - 75.19(8); Cs-F-Cs 104.32(9) $-106.51(9)$. Sum of $C-B-C$ angles $=335.69$ and 336.09 .

Single crystals of Cs[5-F] were obtained from a saturated $\mathrm{MeCN}$ solution at $-25^{\circ} \mathrm{C}$ with its solid state structure consisting of $\left\{\mathrm{Cs}_{2}\left(\mathrm{FBR}_{3}\right)_{2}\right\}$ units propagated into a $1 \mathrm{D}$-coordination polymer by three acetonitrile molecules bridging two adjacent caesium centres (Figure 9, inset right). In Cs[5-F] each $\mathrm{Cs}^{+}$cation is interacting with only five Lewis base donor atoms. Note the only other close contacts involving $\mathrm{Cs}^{+}$in the extended structure of Cs[5-F] are C$\mathrm{H} \cdots \mathrm{Cs}^{+}$interactions with the shortest being $3.133 \AA$, these are presumably significantly weaker interactions than those involving $\mathrm{N} \cdots \mathrm{Cs}^{+} / \mathrm{F} \cdots \mathrm{Cs}^{+} / \mathrm{O} \cdots \mathrm{Cs}^{+}$. Solid state structures of $\mathrm{Cs}\left[\mathrm{FBR}_{3}\right]$ salts are rare, but Aldridge and co-workers have reported monomeric a monomeric example, (18-crown-6)Cs-F-BAryl ${ }_{3}$ (C; Figure 9), in which $\mathrm{Cs}^{+}$is interacting with seven Lewis base donor atoms. ${ }^{20} \mathrm{~A}$ comparison of the two structures is informative with different degrees of aggregation / $\mathrm{Cs}^{+}$ligation significantly effecting key bond distances, in C: $\mathrm{B}-\mathrm{F}=1.496(5) \AA$ and $\mathrm{Cs} \cdots \mathrm{F}=3.034 \AA$, whereas in Cs[5-F]: $B-F=1.524(5) \AA$ and $C s \cdots F=2.945(3) \AA$. . This is consistent with the presence of a more Lewis acidic caesium centre more strongly interacting with the B-F unity, thereby reducing the B-F bond strength. This is consistent with the observed impact of caesium ligation on the ability of fluoroborates to transfer fluoride from boron to carbon electrophiles. The low formal coordination number of $\mathrm{Cs}^{+}$in $\mathrm{Cs}[5-\mathrm{F}]$ may explain the disparity in reactivity between $\mathbf{5}$ and $\mathrm{BEt}_{3}$ towards CSF, particularly in halocarbon solvents. The larger hydrocarbyl groups in $\mathbf{5}$ may prevent additional interactions to $\mathrm{Cs}^{+}$(e.g. formation of higher $\mathrm{Cs}_{n} \mathrm{~F}_{n}$ aggregates containing additional $\mathrm{Cs} \cdots \mathrm{FB}$ interactions) thus leading to unfavourable solvation energetics (and thus no reaction) when $\mathbf{5}$ is combined with CsF in halocarbon solvents. This again emphasises that appropriate ligation of caesium in $\mathrm{Cs}\left[\mathrm{F}-\mathrm{BR} \mathrm{R}_{3}\right]$ is vital alongside the optimal borane fluoride affinity in enabling borane catalysed phase transfer fluorinations.

\section{Conclusions}

Despite the high fluorophilicity of boron, certain organoboranes and boronate esters can be employed as CsF phase-transfer nucleophilic fluorination catalysts. Chiral induction during fluorination with borane catalysts also can be achieved to some extent, however limited catalyst stability under these reaction conditions precludes realising high e.e. in the systems studied to date. Regarding the factors controlling effective catalysis, as expected, nucleophilic fluorination reactivity is impacted by B-F bond strength, which is dependent on borane Lewis acidity towards fluoride. Sufficient fluoride affinity is required for the borane to react with CsF, however if fluoride affinity is too high the resultant fluoroborate does not effectively transfer fluoride to electrophiles. Furthermore, nucleophilic fluorination is most effective under conditions that preclude good ligation of the cation as strong binding of $\mathrm{Cs}^{+}$weakens the $\mathrm{Cs} \cdots \mathrm{F}-\mathrm{B}$ interaction, strengthening the $\mathrm{B}-\mathrm{F}$ bond and thereby leading to less reactive fluoroborates. In terms of predictability, boranes with calculated fluoride affinity of $100-120 \mathrm{~kJ} \cdot \mathrm{mol}^{-1}\left(\mathrm{vs} \mathrm{Me}_{3} \mathrm{Si}^{+}\right)$ appear to be suitable candidates as nucleophilic fluorination catalysts, with the caveat that other factors (e.g. borane stability under the reaction conditions / forming the correct fluoroborate aggregation / $\mathrm{Cs}^{+}$ligation level in solution) are also important to consider. When these prerequisites are met, simple boranes are effective catalysts for nucleophilic fluorination using CsF, including to access useful products (e.g. $\beta$-fluoroamines). Finally, this work highlights that the established dogma that boranes are highly fluorophilic / strong fluoride acceptors, does not always hold. 


\section{Conflicts of interest}

There are no conflicts to declare.

\section{Acknowledgements}

This project has received funding from the European Research Council (ERC) under the European Union's Horizon 2020 research and innovation programme (grant agreement No 769599). We acknowledge SIRCAMS at University of Edinburgh for performing mass spectrometry and Dr. Richard Brewster and Ektoras Yiannakas (both University of Edinburgh) for their kind assistance with chiral HPLC analysis. Prof. G. Lloyd-Jones is thanked for useful discussions.

\section{References}

1 a) I. M. Riddlestone, A. Kraft, J. Schaefer and I Krossing, Angew. Chem., Int. Ed., 2018, 57, 13982-14024; b) H. Böhrer, N. Trapp, D. Himmel, M. Schleep and I. Krossing, Dalton Trans., 2015, 44, 7489-7499.

2 C. R. Wade, A. E. J. Broomsgrove, S. Aldridge and F. P. Gabbaï, Chem. Rev., 2010, 110, 3958-3984.

3 D. R. Willcox, G. S. Nichol and S. P. Thomas, ACS Catal., 2021, 11, 3190-3197.

4 a) C. B. Caputo and D. W. Stephan, Organometallics, 2012, 31, 27-30; b) D. Mandal, R. Gupta and R. D. Young, J. Am. Chem. Soc. 2018, 140, 10682-10686; c) J. Guo, K. L. Bamford and D. W. Stephan, Org. Biomol. Chem., 2019, 17, 5258-5261; d) A. K. Jaiswal, P. K. Prasad and R. D. Young, Chem. Eur. J., 2019, 25, 6290-6294; e) R. Gupta, A. K. Jaiswal, D. Mandal and R. D. Young, Synlett, 2020, 31, 933-937. a) A. J. Cresswell, S. G. Davies, P. M. Roberts and J. E. Thomson, Chem. Rev., 2015, 115, 566-611; b) For recent developments on the Balz-Schiemann reaction, see T. Mohy El Dine, O. Sadek, E. Gras and D. M. Perrin, Chem. Eur. J., 2018, 24, 14933-14937, and references therein.

6 P. Erdmann, J. Leitner, J. Schwarz and L. Greb, ChemPhysChem, 2020, 21, 987-994.

7 a) K. Muller, C. Faeh and F. Diederich, Science, 2007, 317, 1881-1886; b) S. Purser, P. R. Moore, S. Swallow and V. Gouverneur, Chem. Soc. Rev., 2008, 37, 320-330; c) W. K. Hagmann, J. Med. Chem., 2008, 51, 4359-4369; d) R. Berger, G. Resnati, P. Metrangolo, E. Weber and J. Hulliger, Chem. Soc. Rev., 2011, 40, 3496-3508; e) Y. Ogawa, E. Tokunaga, O. Kobayashi, K. Hirai and N. Shibata, iScience, 2020, 23, 101467; f) P. Ertl, E. Altmann and J. M. McKenna, J. Med. Chem., 2020, 63, 8408-8418.

8 For select recent notable, developments in fluoride phase transfer catalysis with substrates relevant to this work see: a) G. Pupo, F. Ibba, D. M. H. Ascough, A. C. Vicini, P. Ricci, K. E. Christensen, L. Pfeifer, J. R. Morphy, J. M. Brown, R. S. Paton and V. Gouverneur, Science, 2018, 360, 638-642; b) G. Pupo, A. C. Vicini, D. M. H. Ascough, F. Ibba, K. E. Christensen, A. L. Thompson, J. M. Brown, R. S. Paton and V. Gouverneur, J. Am. Chem. Soc., 2019, 141, 2878-2883.

For a review on fluorination see: a) M. G. Campbell and T. Ritter, Chem. Rev. 2015, 115, 612-633; For other select recent examples of nucleophilic fluorination see: $b$ ) C. M. Hong, A. M. Whittaker and D. M. Schultz, J. Org. Chem., 2021, 86, 3999-4006; c) S. J. Lee, M. T. Morales-Colón, A. F. Brooks, J. S. Wright, K. J. Makaravage, P. J. H. Scott and M. S. Sanford, J. Org. Chem., 2021, 86, 14124-14130.

10 A. J. Cresswell, S. G. Davies, A. L. A. Figuccia, A. M. Fletcher, D. Heijnen, J. A. Lee, M. J. Morris, A. M. R. Kennett, P. M. Roberts and J. E. Thomson, Tetrahedron Lett., 2015, 56, 3373-3377.

11 a) H. Zhao and F. P. Gabbaï, Org. Lett., 2011, 13, 1444-1446; Note a number of base free [Ar $\left.{ }_{3} \mathrm{BF}\right]^{-}$anions have been shown to react with $[\mathrm{CN}]^{-}$sources to release fluoride for use in fluorinations, see: b) C. Bresner, C. J. E. Haynes, D. A. Addy, A. E. J. Broomsgrove, P. Fitzpatrick, D. Vidovic, A. L. Thompson, I. A. Fallis and S. Aldridge, New J. Chem., 2010, 34, 1652; c) C. Perrio, S. Schmitt, D. Pla, F. P. Gabbaï, K. Chansaenpak, B. Mestre-Voegtle and E. Gras, Chem. Commun., 2017, 53, 340-343. a) D. S. Matteson, Synthesis, 1986, 1986, 973-985; b) H. C. Brown and B. Singaram, Acc. Chem. Res., 1988, 21, 287-293; c) M. M. Midland, Chem. Rev., 1989, 89, 1553-1561; d) H. C. Brown and P. Veeraraghavan Ramachandran, J. Organomet. Chem., 1995, 500, 1-19. S. A. Couchman, D. J. D. Wilson and J. L. Dutton, European J. Org. Chem., 2014, 2014, 3902-3908. The reaction was also conducted at $-25^{\circ} \mathrm{C}$ using a recirculating chiller. After 1 week reaction time, quantitative conversion was achieved, but for 7 e.e. was only $20 \%$. 6 does not react directly with $\mathrm{H}_{2} \mathrm{O}$ or $\mathrm{H}_{2} \mathrm{O}$ / CsF mixtures under these conditions, thus a borane presumably is also catalysing this process to form 10.

16 D. J. Mathre, T. K. Jones, L. C. Xavier, T. J. Blacklock, R. A. Reamer, J. J. Mohan, E. T. T. Jones, K. Hoogsteen, M. W. Baum and E. J. J. Grabowski, J. Org. Chem., 1991, 56, 751-762.

Obtaining pure samples of B-aryl CBS catalysts was not possible in our hands due to purification issues: After initial condensation of the aryl boroxine with the respective prolinol, we found purification was only feasible by sublimation. While 11 sublimed at moderate temperatures (cf. ESI), 4 required $180^{\circ} \mathrm{C}$, a temperature that causes it to decompose via [3+2] cycloreversion (cf. Ref 16), liberating reactive boron species.

18 D. Cubicciotti, J. Chem. Phys., 1961, 34, 2189-2189; and the errata: D. Cubicciotti, J. Chem. Phys., 1961, 34, 2189; D. Cubicciotti, J. Chem. Phys., 1961, 34, 2189. 
S. Thapa, R. K. Dhungana, D. A. Dickie and R. Giri, Tetrahedron, 2019, 75, 4081-4085.

R. Tirfoin, J. A. B. Abdalla and S. Aldridge, Dalton Trans., 2015, 44, 13049-13059. 